\title{
Mineral-scale mobility of PGE and TABS in subducted serpentinites
}

\author{
FERNANDO GERVILLA ${ }^{1,2}$, JOSE MARIA GONZÁLEZ- \\ JIMÉNEZ ${ }^{1,3}$, RUBÉN PIÑA ${ }^{4}$, JAMES SAUNDERS ${ }^{5}$, GAELLE \\ PLISSART $^{6}$, CLAUDIO MARCHESI ${ }^{1}$ AND JOSÉ ALBERTO \\ PADRÓN-NAVARTA ${ }^{7,8}$ \\ ${ }^{1}$ Universidad de Granada \\ ${ }^{2}$ Universidad de Granada Q1818002F \\ ${ }^{3}$ CSIC-UGR \\ ${ }^{4}$ Universidad Complutense de Madrid \\ ${ }^{5}$ Macquarie University \\ ${ }^{6}$ Universidad Austral de Chile \\ ${ }^{7}$ Université de Montpellier \& CNRS \\ ${ }^{8} \mathrm{CSIC}$ (IACT) \\ Presenting Author: gervilla@ugr.es
}

A variety of base-metal minerals (BMM) may form during hydration-dehydration of ultramafic rocks in specific sites and times of the subduction cycle. In particular, subducted serpentinites may contain Ni-rich sulfides, alloys, arsenides and sulfarsenides. In this communication we report the firstever mineralogical study of $\mathrm{Ni}-\mathrm{Fe}-\mathrm{S}-\mathrm{As}$ minerals associated with medium- and high-pressure serpentinites from subducted serpentinites from the La Cabaña area in the Paleozoic Coastal Accretionary Complex of Central Chile. The characteristics of these minerals strongly vary with the degree of serpentinization and style of deformation of the host rock. When olivine was hydrated by (S-As-Sb)-bearing fluids within the mantle wedge the equilibrium opaque assemblage consist of heazlewoodite \pm awaruite \pm magnetite \pm orcelite. Progressive infitlration of these fluids at increasing higher temperatures promoted antigoritization and crystallization of pentalndite \pm gersdorffite within the serpentinitic subduction channel. In contrast, dehydration of the serpentinites under high-pressure conditions gave rise to Ni-rich awaruite in equlibrium with the prograde assemblage antigorite-metamorphic olivine. In situ measurement of trace element on these minerals which may selective partition a wide suite of (semi)-metals ( $\mathrm{Ni}, \mathrm{Fe}, \mathrm{Co}, \mathrm{As}, \mathrm{Sb}, \mathrm{Bi}, \mathrm{Te}, \mathrm{Pb}, \mathrm{Cd}$, $\mathrm{Se}, \mathrm{Cu}, \mathrm{Zn}, \mathrm{Mn}$ ) and precious metals (Os, Ir, Rh, Pt, Pd, Ag), by means of LA-ICP-MS, reveal that Ni-Fe-S-As minerals formed or modified during the entire subduction cycle of upper mantle rocks have their own characteristic traceelement fingerprint. 